\title{
Genetic and Modeling Approaches Reveal Distinct Components of Impulsive Behavior
}

\author{
Katherine M Nautiyal ${ }^{1,2}$, Melanie M Wall ${ }^{1,2,3}$, Shuai Wang ${ }^{2}$, Valerie M Magalong ${ }^{2}$, Susanne E Ahmari ${ }^{4}$, \\ Peter D Balsam ${ }^{2,5}$, Carlos Blanco*,2 and René Hen ${ }^{*, 1,2,6}$
}

'Department of Psychiatry, Columbia University, New York, NY, USA; ' Department of Psychiatry, New York State Psychiatric Institute, New York, NY, USA; ${ }^{3}$ Department of Biostatistics, Mailman School of Public Health, Columbia University, New York, NY, USA; ${ }^{4}$ Department of Psychiatry, Translational Neuroscience Program; Center for Neuroscience Program and Center for the Neural Basis of Cognition, University of Pittsburgh, Pittsburgh, PA, USA; ${ }^{5}$ Psychology Departments, Barnard College and Columbia University, New York, NY, USA; 'Department of Pharmacology, Columbia University, New York, NY, USA

Impulsivity is an endophenotype found in many psychiatric disorders including substance use disorders, pathological gambling, and attention deficit hyperactivity disorder. Two behavioral features often considered in impulsive behavior are behavioral inhibition (impulsive action) and delayed gratification (impulsive choice). However, the extent to which these behavioral constructs represent distinct facets of behavior with discrete biological bases is unclear. To test the hypothesis that impulsive action and impulsive choice represent statistically independent behavioral constructs in mice, we collected behavioral measures of impulsivity in a single cohort of mice using well-validated operant behavioral paradigms. Mice with manipulation of serotonin IB receptor $\left(5-\mathrm{HT}_{\mid \mathrm{B}} \mathrm{R}\right)$ expression were included as a model of disordered impulsivity. A factor analysis was used to characterize correlations between the measures of impulsivity and to identify covariates. Using two approaches, we dissociated impulsive action from impulsive choice. First, the absence of 5-HT $\mathrm{HB}_{\mathrm{B}} \mathrm{Rs}$ caused increased impulsive action, but not impulsive choice. Second, based on an exploratory factor analysis, a two-factor model described the data well, with measures of impulsive action and choice separating into two independent factors. A multiple-indicator multiple-causes analysis showed that $5-\mathrm{HT}_{\mathrm{IB}} \mathrm{R}$ expression and sex were significant covariates of impulsivity. Males displayed increased impulsivity in both dimensions, whereas $5-\mathrm{HT}_{\mathrm{IB}} \mathrm{R}$ expression was a predictor of increased impulsive action only. These data support the conclusion that impulsive action and impulsive choice are distinct behavioral phenotypes with dissociable biological influences that can be modeled in mice. Our work may help inform better classification, diagnosis, and treatment of psychiatric disorders, which present with disordered impulsivity. Neuropsychopharmacology (2017) 42, II82-1191; doi:I0.1038/npp.2016.277; published online I8 January 2017

\section{INTRODUCTION}

Impulsive behavior is a core endophenotype of many psychiatric disorders, including personality disorders, substance use disorders, gambling disorder, and attention deficit hyperactivity disorder (ADHD) (Blanco et al, 2009; Dawe and Loxton, 2004; Moeller et al, 2001; Swann, 2011). The lifetime prevalence of disordered impulse control is $17 \%$ in the general US population; and disordered impulse control is associated with many negative effects, including reckless, suicidal, illegal, and violent behavior (Chamorro et al, 2012; Michaelis et al, 2004; Perez-Moreno et al, 2015). However, there are very few effective treatments for impulsivity, and a better understanding of the biological

* Correspondence: Professor R Hen or Dr C Blanco, Center for Neurobiology and Behavior, Columbia University, 722 W. I 68th St., P.I. Annex 731, I05I Riverside Drive, Unit 87, New York, NY I0032, USA, Tel: 212646774 7I04, Fax: 212646774 7I02,

E-mail: rh95@columbia.edu or cb255@cumc.columbia.edu

Received 17 August 2016; revised 24 November 2016; accepted 2 December 2016; accepted article preview online I5 December 2016 basis of normal and pathological impulsivity could help inform a more dimensional, biologically based classification of psychiatric disorders and provide clues for more effective treatments.

It has become increasingly clear that impulsivity is a heterogeneous phenotype that can have multiple components (Berg et al, 2015; Broos et al, 2012; MacKillop et al, 2016; Robbins et al, 2012; Winstanley et al, 2004). Two commonly considered components are impulsive action and impulsive choice (Wang et al, 2016; Winstanley et al, 2004). The former is characterized as acting prematurely and/or having difficulty inhibiting responses and is frequently measured in humans and rats using stop-signal reaction time tasks and go/no-go paradigms (Bari and Robbins, 2013; Weafer et al, 2013). By contrast, impulsive choice is described as decreased tolerance to delays or disordered risk-based decision making and is most commonly measured using delay discounting paradigms (Mar and Robbins, 2007; Story et al, 2015). Attention, hyperactivity, and motivation have also been considered as factors contributing to impulsive behavior (Frijda, 2010; Hepler et al, 2012). 
A better understanding of the behavioral structure of impulsivity could improve treatment for psychiatric disorders in which impulsive behavior is a key symptom. The different dimensions of impulsive behavior are likely mediated by distinct neural circuits, and contribute differentially to various psychiatric disorders (Dalley et al, 2011; Robbins et al, 2012). Analysis of human behavioral data has shown that variables from paradigms measuring impulsive action and impulsive choice can generally be dissociated into two or more independent factors (Dougherty et al, 2009; Meda et al, 2009; Reynolds et al, 2006; Reynolds et al, 2008). Work investigating similar factors in animal models has mostly used between subject designs or pharmacological/ lesion manipulations, which are suboptimal for the determination of the baseline multi-dimensional construction of impulsive behavior (Barrus et al, 2015; Broos et al, 2012). Rodent and human studies have strongly implicated dopaminergic signaling in the modulation of impulsive behavior (Dalley et al, 2007; St Onge and Floresco, 2009; Winstanley, 2011). However, serotonergic signaling has also been shown to be an important contributor to the neural basis of impulsivity, affecting both impulsive action and impulsive choice domains (Miyazaki et al, 2012; Miyazaki et al, 2014; Winstanley et al, 2003, 2004; Worbe et al, 2014).

To examine whether impulsive action and impulsive choice represent independent, non-correlated behavioral constructs in mouse models, we collected within subject data from multiple well-validated operant behavioral tests of impulsivity. Mice that lacked serotonin $1 \mathrm{~B}$ receptors (5- $\left.\mathrm{HT}_{1 \mathrm{~B}} \mathrm{Rs}\right)$ throughout life $\left(5-\mathrm{HT}_{1 \mathrm{~B}} \mathrm{R} \mathrm{KO}\right)$ were included as a model of disordered impulsivity, given their known deficits in tasks measuring impulsive action (Brunner and Hen, 1997; Nautiyal et al, 2015). We also used mice lacking $5-\mathrm{HT}_{1 \mathrm{~B}} \mathrm{R}$ expression only during development, in which $5-\mathrm{HT}_{1 \mathrm{~B}} \mathrm{R}$ expression was rescued during adulthood $\left(5-\mathrm{HT}_{1 \mathrm{~B}} \mathrm{R}\right.$ rescue) based on our previous studies showing that adult rescue of the receptor also rescues the impulsive phenotype of the knockouts. Our studies provide evidence that impulsive action and choice are independent components of impulsivity that have distinct underlying biological bases. First, we show that altering the levels of the $5-\mathrm{HT}_{1 \mathrm{~B}} \mathrm{R}$ modulates impulsive action, but not impulsive choice. Second, using factor analysis, our results demonstrate that measures of these two behaviors dissociate into independent components. We find that $5-\mathrm{HT}_{1 \mathrm{~B}} \mathrm{R}$ expression is a significant predictor of impulsive action, whereas sex is a significant covariate of both components with males displaying increased impulsivity. Taken together, our results show a dissociation of impulsive action from impulsive choice and point to a biological mechanism for the impulsive action component.

\section{MATERIALS AND METHODS}

\section{Animals}

Mice were bred in the Department of Comparative Medicine animal facility at the New York State Psychiatric Institute at the Columbia University Medical Center. The floxed tetO1B mouse model was used to generate groups of mice with alterations in $5-\mathrm{HT}_{1 \mathrm{~B}} \mathrm{R}$ expression (Nautiyal et al, 2015). Mice were generated by pairing a homozygous tetO1B female with a homozygous tetO1B male that was also heterozygous for the $\beta$ actin-tTS transgene. Three groups of mice, totaling 59 mice, were used in all behavioral tests: tetO1B+/+::ßactintTS + mice (referred to as $5-\mathrm{HT}_{1 \mathrm{~B}} \mathrm{R} \mathrm{KO}, \mathrm{N}=14$ ), tetO1B+/+:: $\beta$ actin-tTS + treated with doxycycline beginning at P60 (referred to as adult rescue, $N=14$ ), and their littermate tetO1B+/+::ßactin-tTS- controls (referred to as controls, $\mathrm{N}=31$ ). Doxycycline was administered in the chow $\left(40 \mathrm{mg} / \mathrm{kg}\right.$, Bioserv) to rescue $5-\mathrm{HT}_{1 \mathrm{~B}} \mathrm{R}$ expression. Males $(N=23)$ and females $(N=36)$ were included. Mice were group housed with same sex littermates following weaning at postnatal day (PN) 21. Food and water were provided ad libitum except during operant behavioral experiments as described below, which began at 12-14 weeks of age. Animals were maintained on a $12 \mathrm{~h}: 12 \mathrm{~h}$ light-dark cycle and all behavioral testing was conducted during the light cycle. Differential reinforcement of low-rate responding (DRL) and Go/No-Go (GNG) tasks were used to assess premature responding and behavioral inhibition. Delay discounting (DD) and probabilistic discounting (PD) were used to measure impulsive choice, and a progressive ratio schedule of operant responding and the open field test were used to measure motivation and hyperactivity. Mice were tested in behavioral paradigms in the following order: DRL, PR, open field test, GNG, DD, and PD. All animal care and testing was approved by the Institutional Animal Use and Care Committee and was in accordance with the NIH's Guide for the Care and Use of Laboratory Animals.

\section{Operant Conditioning}

Studies were conducted in eight identical operant chambers $(15.9 \times 14.0 \times 12.7) \mathrm{cm}$ with stainless steel grid flooring illuminated by a house light (Med Associates Inc., St Albans, VT), individually enclosed in sound-insulating, ventilated cubicles. Each chamber had two ultra-sensitive retractable stainless steel levers placed $2.2 \mathrm{~cm}$ above the chamber floor situated on either side of a receptacle equipped with head entry detection for delivery of liquid reward. The dipper delivered 0.02cc evaporated milk (Wakefern Food Corporation, Elizabeth, NJ) to mice. A Dell computer equipped with MED-PC IV (Med Associates Inc., St Albans, VT) computer software delivered stimuli and collected behavioral data. Operant training and testing were run 7 days a week. Mice were maintained at $\sim 90 \%$ of their free-feeding weight by providing ad libitum access to chow for $1.5 \mathrm{~h}$ following each day's operant conditioning session during the light cycle. Water was provided ad libitum throughout the experiment. There was no significant effect of group on body weight $\left(\mathrm{F}_{2,38}=2.2, p>0.05\right)$, or consumption of chow over $1 \mathrm{~h}$ while maintained on this restricted feeding schedule $\left(\mathrm{F}_{2,38}=1.4\right.$, $p>0.05$ ), which was evaluated in a random subset of these mice.

Mice were first trained to retrieve an evaporated milk reward through head entry into the receptacle. Following 5 days of training, all mice met the criterion of retrieving at least 28 of the 30 rewards within $8 \mathrm{~s}$ of their presentation. Next, mice were trained to press a lever to receive the evaporated milk reward on a fixed ratio-1 (FR-1) schedule. A small dab of Ferret Nutri-cal (Tomlyn, Fort Worth, TX) was placed on the lever to facilitate initial interaction with the lever. Mice were trained in this paradigm until the criterion of 55 lever presses in a 60 min session was reached. Each 
mouse was trained on a randomly assigned (left or right) lever, which remained consistent for DRL, PR, and go/no-go paradigms.

\section{Differential Reinforcement of Low-Rate Responding}

Following shaping, mice were trained on the DRL paradigm with a $36 \mathrm{~s}$ target wait time (DRL-36). Responses before $36 \mathrm{~s}$ were not rewarded, and the 'wait timer' restarted. Mice were gradually trained to wait $36 \mathrm{~s}$ over 44 days, beginning with a delay of $4 \mathrm{~s}$ and followed by increasing intervals of $2 \mathrm{~s}$. All daily sessions lasted $1 \mathrm{~h}$ or until 60 rewards were reached. Data from the final 5 days of DRL-36 was averaged and used for analysis. The number of burst responses (lever presses with latencies of $<3 \mathrm{~s}$ ) and the mode of response latencies (used as a representative measure of premature responding) were used as inputs for the factor analysis. The mode of response latencies was the mathematical mode taken on the response latencies converted to integers (by removing the fraction of the second).

\section{Progressive Ratio}

Following the DRL paradigm, mice were run on a PR schedule to assess motivation-like responding. Mice were initially re-trained for 3 days on a FR-1 schedule, followed by 3 days on each of random ratio (RR)-5, RR-10, and RR-20 schedules, before testing on a $\mathrm{PR} \times 2$ schedule in which the number of lever presses required to receive a reward doubled following each reward. The session ended following either $2 \mathrm{~h}$, or a $3 \mathrm{~min}$ period in which no lever presses were recorded (Drew et al, 2007). The total number of lever presses summed over the session, and the break point were analyzed. The total number of lever presses rather than break point was used in the factor analysis to provide a continuous rather than categorical variable.

\section{Open Field}

A standard assay of open field was used to assess baseline activity. Mice were placed individually into a plexiglass enclosure $43 \times 43 \mathrm{~cm}$ in size (Med Associates) and allowed to explore undisturbed for $30 \mathrm{~min}$. Movements were recorded by beam breaks of two sets of 16 infrared photobeams, and summed across the $30 \mathrm{~min}$ period for the factor analysis.

\section{Go/No-Go}

Mice were first trained on Go trials in which they were required to press a lever within $5 \mathrm{~s}$ of its presentation to receive a reward. If the $5 \mathrm{~s}$ elapsed with no response, the lever would retract, no reward would be presented, and a new ITI (average $40 \mathrm{~s}$ ) would begin. Mice were trained on these $5 \mathrm{~s}$ Go-only trials until they earned at least 50 rewards out of 60 trials for at least two consecutive sessions. Once this criterion was achieved, No-Go trials were added in which the lever was presented simultaneously with two cues (the house lights turning off, and a small LED light above the lever turning on). A lack of any lever press within $5 \mathrm{~s}$, resulted in a reward. A lever press during this period caused the lever to retract, the house lights to turn on, the LED light to turn off, and a new ITI to begin without any reward for that trial. In each session, 30 Go trials were interspersed with 30 No-Go trials presented pseudorandomly such that there were an equal number of both kinds of trials in every block of 10 trials. Mice were run for 12 days, and the percent false alarms (number of incorrect No-Go trials/total number of No-Go trials $\times 100$ ) and hits (number of correct Go trials/total number of Go trials $\times 100)$ were analyzed. There was no significant day by group interaction $\left(\mathrm{F}_{22,605}=1.1, p>0.05\right)$, so values on day 12 were used in the factor analysis.

\section{Delay Discounting}

Following the Go/No-Go paradigm, mice were trained to press the opposite lever from their original training and all mice met criteria (55 presses in $60 \mathrm{~min}$ ) within two sessions. Mice were then presented with both levers for 4 days, with both levers rewarded on a FR-1 schedule. Their preferred lever was determined (as the lever with more presses), which remained consistent across days. Next, presses on the nonpreferred lever were rewarded with three times the reward obtained from presses on the originally preferred lever. The large reward was implemented by having the dipper arm present three rewards in succession. These sessions began with 10 forced choice trials (five on each lever randomly distributed) to ensure a minimum experience with each lever in each session. Over 14 days, the preference of all mice switched to large reward lever. Finally, the DD paradigm began in which mice experienced a step-wise increase in the delay to the availability of the large reward following a lever press, across sessions. These sessions also began with five forced choice trials on each lever. The delay to the small reward remained at $0 \mathrm{~s}$. Time delays $(2,4,6,8$, and $10 \mathrm{~s})$ were presented in separate sessions for 3 days each, in ascending order. Thirty trials were presented in each session, regardless of delay length and choice. The large reward was always three times the amount of the small reward. Data were used from the last session of each time delay to allow for learning of the new contingency. There were no interactions between group and day within any given delay $\left(\mathrm{F}_{4,108}<1.8, p>0.05\right)$. The preference for the large reward was determined for each delay by dividing the number of presses on the large reward lever by the total number of presses. The discounting slope was determined by calculating the linear regression of preference for large reward plotted over delay, and used in the factor analysis.

\section{Probabilistic Discounting}

The PD paradigm consisted of a step-wise decrease in the probability of presentation of the large reward. Each probability of obtaining the large reward $(0.8,0.6,0.5,0.4$, $0.33,0.2)$ was presented for 3 days, and only data from the last session of each reward probability was used in the analysis. The large reward was three times the small reward, making the large reward more advantageous on all probabilities $>0.33$. The probabilities were presented in separate sessions in the same manner as described for the DD paradigm. On non-rewarded trials, the ITI began $5 \mathrm{~s}$ following the lever press. The probability of the small reward remained at 1.0 throughout all sessions. These sessions also began with five forced choice trials on each lever, followed by 
30 choice trials. Data were used from the last session of each probability to allow for learning of the new contingency. There were no interactions between group and day within any given probability $\left(\mathrm{F}_{6,106}<1.1, p>0.05\right)$. Preference for the large lever was determined for each probability by dividing the number of presses on the large reward lever by the total number of presses. The discounting slope was determined by calculating the linear regression of preference for large reward plotted over probability, and used in the factor analysis.

\section{Statistical Analysis}

One-way analysis of variance (ANOVA) was used to assess the effects of $5-\mathrm{HT}_{1 \mathrm{~B}} \mathrm{R}$ expression on behavior. Repeated measures ANOVAs were used to examine false alarm and hit rates over time in the Go/No-Go paradigm and preference for large reward over delays and probabilities for DD and PD paradigms, respectively. Fisher's least significant differences test was used for post hoc testing when appropriate. Twoway ANOVAs $\left(5-\mathrm{HT}_{1 \mathrm{~B}} \mathrm{R}\right.$ expression $\times$ doxycycline administration) and three-way ANOVAs ( $\mathrm{ex} \times 5-\mathrm{HT}_{1 \mathrm{~B}} \mathrm{R}$ expression $\times$ doxycycline administration) were also performed to assess interactions of adult expression, genotype, and sex on behavior (Supplementary Table 1). Exploratory factor analysis with geomin rotation was used to examine the latent structure of impulsive behavior in mice. Eigenvalues
$>1$ were used to identify the number of factors and calculate the percent of variability in the behavioral measures explained by the latent factors. Determination of whether each paradigm was related to the latent factors was made based on tests for each factor loading equal to zero. A confirmatory factor analysis model with loadings set to zero was then assessed via standard indices, including the chisquare goodness of fit test, root mean squared error of approximation (RMSEA), comparative fit index (CFI), and Tucker-Lewis index (TLI). Following Muthen and Muthen (1998-2010), a $p$-value $>0.05$ for the chi-square goodness of fit test, CFI $>0.95$, TLI $>0.95$, and RMSEA $<0.06$ were used to indicate good model fit. After the latent structure was identified, a multiple-indicators multiple-causes (MIMIC) approach (Joreskog and Goldberger, 1975) was used to assess the effects of covariates $\left(5-\mathrm{HT}_{1 \mathrm{~B}} \mathrm{R}\right.$ expression, sex) on the latent factors. The MIMIC approach permits testing of multiple covariates and provides estimates of the relationship between the covariates and the latent factors. The estimates indicate the number of standard deviations difference in the latent factor for each level of the categorical covariate (eg, sex, 5- $\mathrm{HT}_{1 \mathrm{~B}} \mathrm{R}$ expression) while holding the other covariates constant. Effects were considered statistically significant when $p$-values were $<0.05$. Number of hits in the Go/No-Go task was right skewed and hence was log transformed for analyses to satisfy normality assumptions for exploratory factor analysis. StatView software was used
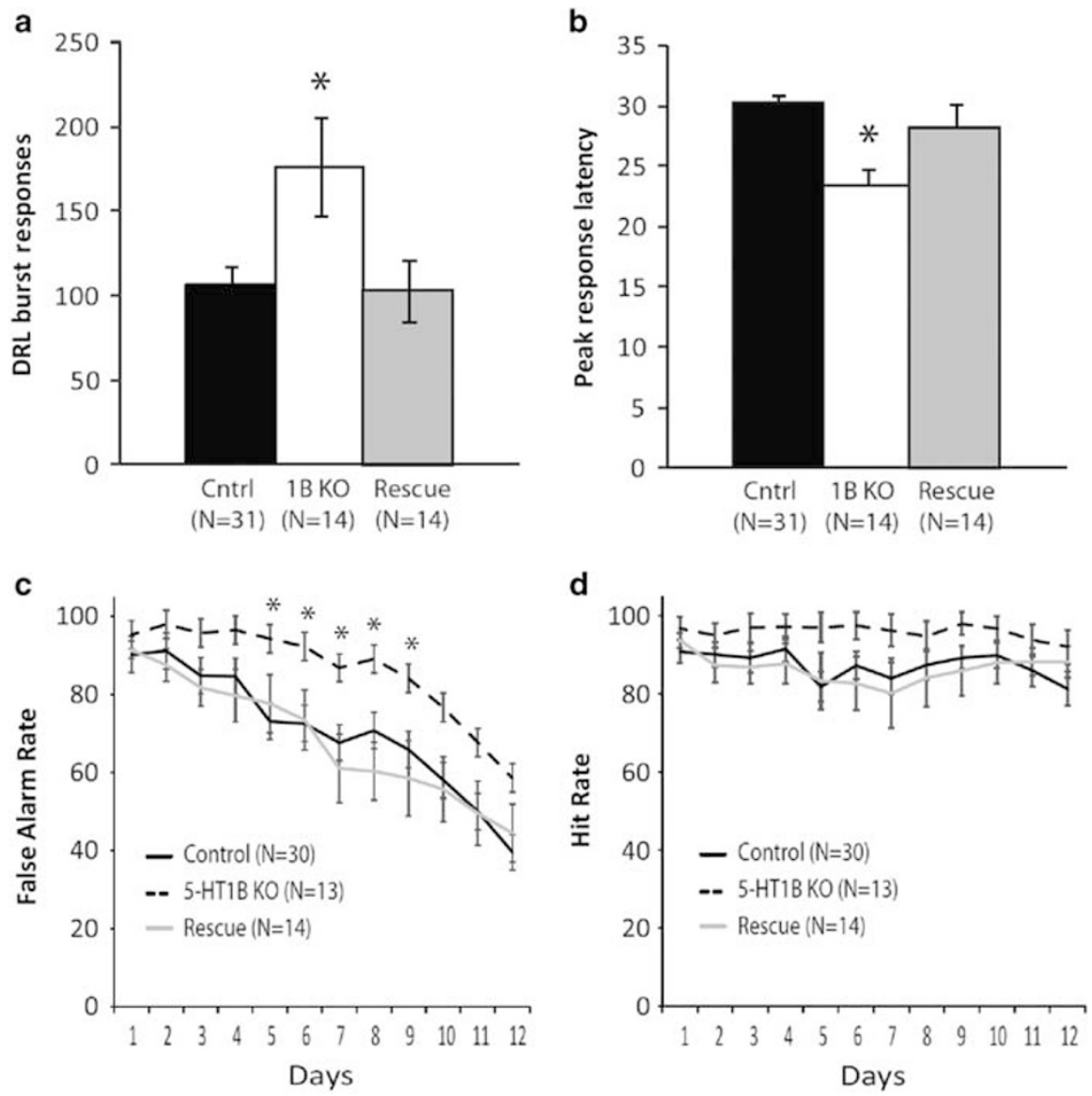

Figure I Measures of premature responding and behavioral inhibition from tests of DRL (a,b) and GNG (c,d) are shown. *, $p<0.05$. 
for ANOVAs, and Mplus software was used for factor and MIMIC analyses.

\section{RESULTS}

A lack of $5-\mathrm{HT}_{1 \mathrm{~B}} \mathrm{R}$ expression resulted in increased levels of impulsivity as measured in the DRL and GNG operant paradigms, as previously reported (Nautiyal et al, 2015). Specifically, in the DRL, there was a significant effect of $5-\mathrm{HT}_{1 \mathrm{~B}} \mathrm{R} \mathrm{KO}$ on burst responding (Figure 1a; main effect of group: $\left.\mathrm{F}_{2,56}=4.81, p<0.05\right)$ with $5-\mathrm{HT}_{1 \mathrm{~B}} \mathrm{R} \mathrm{KO}$ mice having increased number of burst responses compared to controls $(p<0.01)$. This deficit was reversed with adult rescue of $5-\mathrm{HT}_{1 \mathrm{~B}} \mathrm{R}$ expression $\left(p<0.05\right.$ for rescue $v s 5-\mathrm{HT}_{1 \mathrm{~B}} \mathrm{R} ; p>0.05$ for rescue $v s$ control). Additionally, there was a significant effect of $5-\mathrm{HT}_{1 \mathrm{~B}} \mathrm{R}$ expression on the peak of the response latencies (Figure 1b; main effect of group: $\mathrm{F}_{2,56}=8.33$, $p<0.001$ ), representative of a left-shift in the lever press response distribution (Supplementary Figure 1). 5- $\mathrm{HT}_{1 \mathrm{~B}} \mathrm{R}$ KOs had decreased peak response latency compared with controls $(p<0.001)$, which was also reversed by adult rescue $\left(p<0.05\right.$ for rescue $v s 5-\mathrm{HT}_{1 \mathrm{~B}} \mathrm{R} \mathrm{KO} ; p>0.05$ for rescue $v s$ control).

In the Go/No-Go operant paradigm, all mice improved their performance over 12 days of testing, decreasing their impulsive behavior as measured by false alarm rate or the inability to withhold responses on No-Go trials (Figure 1c; main effect of days: $F_{11,605}=36.8, p<0.001$ ). There also were significant group effects on false alarm rates over the 12 days (main effect of group: $\mathrm{F}_{2,55}=4.6, p<0.05$ ), with $5-\mathrm{HT}_{1 \mathrm{~B}} \mathrm{R}$ $\mathrm{KO}$ mice having significantly higher false alarm rates than the control $(p<0.01)$ and adult rescue groups $(p<0.05)$. There were no significant effects of group on hit rates over the 12 days (Figure 1d; main effect of group: $F_{2,55}=2.1$, $p>0.05)$.

By contrast with its effect on DRL and Go/No-Go tests, we found no effect of $5-\mathrm{HT}_{1 \mathrm{~B}} \mathrm{R}$ expression on discounting in delay discounting and probabilistic discounting paradigms. All mice showed discounting of reward as delays increased or probabilities decreased, as seen by their decreased preference for the large reward in both delay and probabilistic discounting tasks (Figure 2a and b; main effect of delay: $\mathrm{F}_{4,192}=198.2, p<0.001$ for $\mathrm{DD}$; main effect of probability: $\mathrm{F}_{6,318}=38.0, p<0.001$ for $\left.\mathrm{PD}\right)$. There were no significant genotype by time interactions $\left(\mathrm{F}_{2,8}=1.41, p>0.05\right.$ for $\mathrm{DD}$; $\left.\mathrm{F}_{2,12}=0.89, p>0.05\right)$, suggesting that the discounting rate did not differ between groups. There was also a lack of significant group differences in the slopes of best fit lines for delay and probabilistic discounting data (Figure 2 insets; main effect of group: $F_{2,52}=1.32, p>0.05$ for DD; $\mathrm{F}_{2,52}=1.86, p>0.05$ for PD). However, there were significant effects of group on reward preference, independent of discounting, in both tasks $\left(\mathrm{F}_{2,54}=4.08, p<0.05\right.$ for $\mathrm{DD}$; $\mathrm{F}_{2,53}=5.75, p<0.01$ for PD). Specifically, $5-\mathrm{HT}_{1 \mathrm{~B}} \mathrm{R} \mathrm{KO}$ mice showed increased preference for large rewards compared with control mice over all delays $(p<0.01)$ and probabilities $(p<0.01)$, potentially pointing to an effect of $5-\mathrm{HT}_{1 \mathrm{~B}} \mathrm{R}$ on hedonic and/or incentive value. However, there were no significant effects of group on the preference for a small $v s$ large (three times the small) reward in the absence of any delays or probabilities $\left(F_{2,48}=2.3, p>0.05 ; 77.4 \pm 2.5 \%\right.$ for
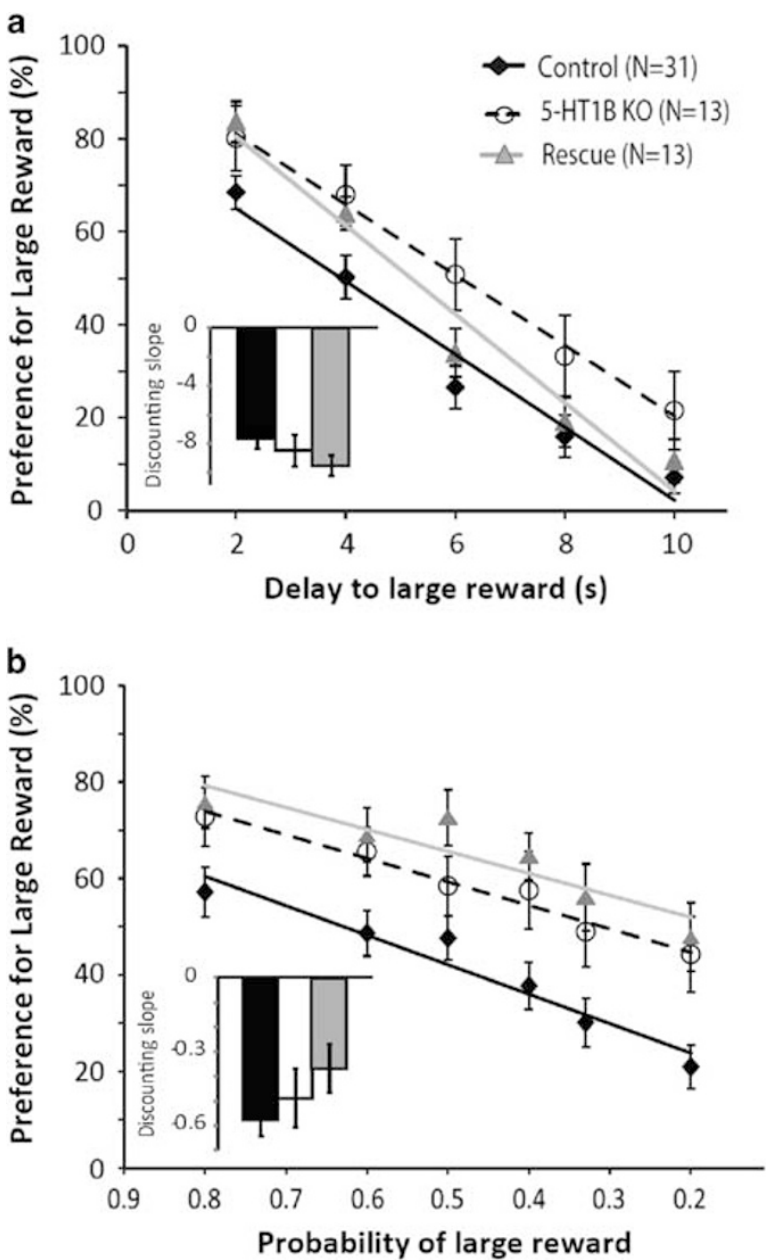

Figure 2 Measures of intolerance to delays and risk are shown as preference for the large reward over various delays in DD (a) and various probabilities in PD (b) paradigms. Insets show rates of discounting for each group.

controls; $85.5 \pm 4.0 \%$ for $5-\mathrm{HT}_{1 \mathrm{~B}} \mathrm{R} \mathrm{KO} ; 86.1 \pm 4.4 \%$ for adult rescue). Interestingly, for probabilistic discounting, there was a sex by genotype interaction (Supplementary Figure 2; $\left.\mathrm{F}_{1,49}=5.025, p<0.05\right)$, in which $5-\mathrm{HT}_{1 \mathrm{~B}} \mathrm{R} \mathrm{KO}$ and adult rescue males showed significantly steeper discounting than control males (main effect of group within males: $\mathrm{F}_{2,20}=3.612, p<0.05 ; p=0.07$ for KO vs control; $p<0.05$ for rescue $v s$ control), and there was no difference seen between female groups (main effect of group within females: $\left.\mathrm{F}_{2,31}=0.4, p>0.05\right)$. This suggests that although there was not an effect of $5-\mathrm{HT}_{1 \mathrm{~B}} \mathrm{R} \mathrm{KO}$ on discounting, there may be a developmental effect of $5-\mathrm{HT}_{1 \mathrm{~B}} \mathrm{R}$ expression in males only.

There was no effect of $5-\mathrm{HT}_{1 \mathrm{~B}} \mathrm{R}$ expression on open field activity (Figure 3a; main effect of group: $F_{2,55}=0.5, p>0.05$ ). However, there was a significant genotype effect on performance in the progressive ratio task (Figure $3 \mathrm{~b}$; main effect of genotype: $\left.\mathrm{F}_{2,56}=28.6, p<0.001\right)$. $5-\mathrm{HT}_{1 \mathrm{~B}} \mathrm{R} \mathrm{KO}$ mice had a break point more than twice as high as controls and adult rescue groups $\left(5-\mathrm{HT}_{1 \mathrm{~B}} \mathrm{R} \mathrm{KO}: 1536 \pm 142\right.$, controls: $606 \pm 84$, adult rescue: $626 \pm 213 ; p<0.001)$. Additionally, they had more than three times the number of lever presses 

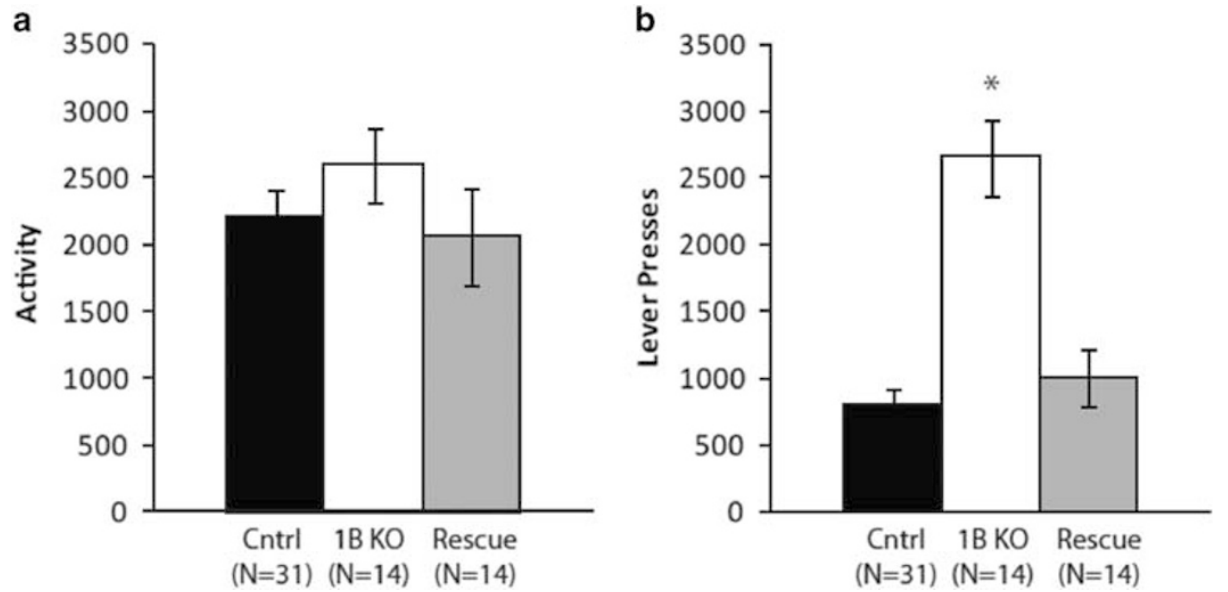

Figure 3 Measures of activity and motivation are shown from the open-field test (a) and progressive ratio schedule of operant responding (b).

Table I Two-Factor Model

\begin{tabular}{lrr}
\hline & Factor I & Factor \\
\hline DRL: burst responses & $\mathbf{0 . 7 1 7}$ & -0.008 \\
DRL: peak response latency & $-\mathbf{0 . 6 7 8}$ & -0.153 \\
Go/No-Go: false alarm rate & $\mathbf{0 . 5 7 1}$ & 0.145 \\
Go/No-Go: hit rate & $\mathbf{0 . 4 3 6}$ & 0.042 \\
Open field activity & $\mathbf{0 . 3 6 2}$ & -0.064 \\
Progressive ratio lever presses & $\mathbf{0 . 8 5 8}$ & -0.008 \\
Delayed discounting slope & 0.005 & $\mathbf{0 . 4 6 4}$ \\
Probabilistic discounting slope & -0.001 & $\mathbf{1 . 0 0 3}$ \\
Correlation of factors & 1.000 & \\
& 0.209 & 1.000 \\
\hline
\end{tabular}

Significant factor loadings (absolute value $>0.3$ ) are bolded.

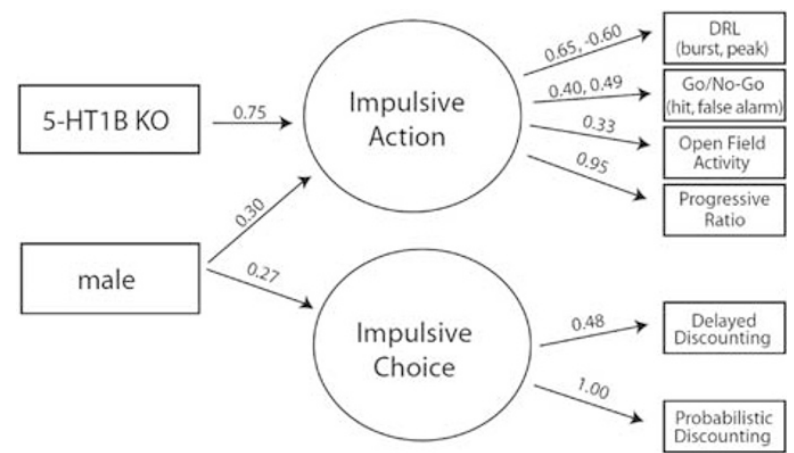

Figure 4 All effects shown in this multiple indicator multiple causes (MIMIC) model are significant $(p<0.05)$.

compared with control $(p<0.001)$ and adult rescue groups $(p<0.001)$.

An exploratory factor analysis of all the behavioral data found two eigen values above one (eigen values $=3.08,1.39$, $0.95,0.71,0.66,0.57,0.37$, and 0.26 ) supporting a two-factor model that explained $56 \%$ of the variability in the data (Table 1). Variables from DRL, Go/No-Go, progressive ratio, and open field measures loaded significantly onto one factor, whereas variables from delay and probabilistic discounting paradigms loaded significantly onto the other. These latent factors were called 'impulsive action' and 'impulsive choice', respectively. All variables loaded positively onto the two factors with the exception of the DRL peak response latency given its inverse relationship with impulsivity (lower-peak latencies represent higher levels of impulsivity). The correlation between the two factors was not significant $(r=0.209, p>0.05)$. A confirmatory two-factor model fixing all non-significant loadings to zero provided a good fit for the data: $\chi^{2}=14.5, \mathrm{df}=19, p$-value $=0.74$, RMSEA $<0.001$, $\mathrm{CFI}=1.00, \mathrm{TLI}=1.07$. The addition of a third factor did not improve the fit of the model (Supplementary Table 2). Only one variable from the impulsive action factor (Go/No-Go false alarm rate) loaded onto the additional factor, which remained highly correlated with the impulsive action factor $(r=0.561)$.

An exploratory factor analysis was also run on a subset of the mice, which excluded all $5-\mathrm{HT}_{1 \mathrm{~B}} \mathrm{R} \mathrm{KO}$ and $5-\mathrm{HT}_{1 \mathrm{~B}} \mathrm{R}$ rescue mice, to rule out contributions of genotype on the latent structure. The same factor loadings indicating 'impulsive action' and 'impulsive choice' were found to be significant in a two-factor model (Supplementary Table 3) with the first two eigen values, ie, 3.12 and 1.70, indicating $60 \%$ of the variability in the data was explained by these two factors. Additionally, the correlation between the two factors was not significant $(r=-0.002)$.

The multiple indicator multiple causes model (Figure 4) indicated that the $5-\mathrm{HT}_{1 \mathrm{~B}} \mathrm{R}$ knockout influenced the two latent factors differently $(p<0.001)$. Specifically, it was a significant predictor of impulsive action $(\beta=0.75, p<0.001)$, but not impulsive choice $(\beta=0.11, p>0.05)$, indicating that an absence of $5-\mathrm{HT}_{1 \mathrm{~B}} \mathrm{R}$ resulted in increased impulsive action but not impulsive choice. Interestingly, sex was also a significant covariate in the model, with males showing significantly higher impulsive action $(\beta=0.30, p<0.01)$ and impulsive choice $(\beta=0.27, p<0.05)$. Additionally adult rescue of $5-\mathrm{HT}_{1 \mathrm{~B}} \mathrm{R}$ (doxycycline administration) was a significant covariate of impulsive choice $(\beta=0.25, p<0.05)$, but not impulsive action $(\beta=0.11, p>0.05)$. The correlation between the two factors was not significant $(r=0.12$, $p>0.05)$. 


\section{DISCUSSION}

Our results show that impulsive behavior can be dissociated into two dimensions of impulsive action and impulsive choice based on two independent methods. First, we show that an absence of $5-\mathrm{HT}_{1 \mathrm{~B}} \mathrm{Rs}$ throughout the brain results in increased impulsivity in tasks that measure premature responding or response inhibition (impulsive action), but not in tasks that measure delayed gratification or risky decision making (impulsive choice). Second, our factor analysis on measures from a number of behavioral tasks reveals two independent components of impulsivity. Furthermore, we show that genetic manipulation of $5-\mathrm{HT}_{1 \mathrm{~B}} \mathrm{R}$ is a predictor of only one dimension (impulsive action), whereas sex is a significant predictor of both dimensions, with males having increased impulsive action and impulsive choice. These results demonstrate that preclinical modeling of impulsivity using current transgenic models allows for a controlled investigation of common and independent sources of variability, which contribute to the different subcomponents of impulsive behavior, as well as more targeted investigations into their neural and genetic basis.

The results presented are consistent with evidence that supports distinct neural bases for impulsive choice and impulsive action in both humans and rodents (Dougherty et al, 2009; Meda et al, 2009; Reynolds et al, 2006; Reynolds et al, 2008). Our use of a genetic model tested in a number of domains of impulsivity in a within-subjects design, analyzed using an unsupervised factor analysis now adds to this evidence. Genetic models allow for future circuit level determination of the neural substrates, as well as the identification of genetic-based risk factors for different facets of impulsivity. Additionally, we found that the impulsive action and impulsive choice factors were not correlated in our model, which is consistent with some, but not all, studies addressing this using within subject designs in rodents (Broos et al, 2012; Van den Bergh et al, 2006a; Winstanley et al, 2004; Barrus et al, 2015). Analyses using self-report and behavioral measures of impulsivity in humans have also shown mixed results. Some studies show no significant correlation between different components of impulsivity (Broos et al, 2012; McDonald et al, 2003; Reynolds et al, 2008), whereas others show positive correlations between action and choice dimensions of impulsivity (Dougherty et al, 2009; Meda et al, 2009). Ultimately, consistent with the research domain criteria initiative and the goals of precision medicine (Health, 2015; Insel and Cuthbert, 2015), research focused on clarifying the domains of impulsive behavior can also lead to better diagnosis and more effective treatments of individuals presenting with disordered impulse control, such as $\mathrm{ADHD}$, substance use disorder, and gambling disorder.

Both basic and clinical research have pointed to a role for $5-\mathrm{HT}_{1 \mathrm{~B}} \mathrm{R}$ as a major regulator of impulsivity. Although genetic mouse models have previously implicated $5-\mathrm{HT}_{1 \mathrm{~B}} \mathrm{Rs}$ in $\mathrm{DRL}$, other studies have revealed a limited role for $5-\mathrm{HT}_{1 \mathrm{~B}} \mathrm{Rs}$ in delay discounting tasks (Brunner and Hen, 1997; Nautiyal et al, 2015; Pattij et al, 2003; van den Bergh et al, 2006b). In humans, gene-association studies and haplotype and meta-analyses have illustrated strong links between $5-\mathrm{HT}_{1 \mathrm{~B}} \mathrm{R}$ polymorphisms and trait impulsivity, susceptibility to suicide, and disorders which include impulsivity as a key phenotype, such as ADHD (Banerjee et al,
2012; Conner et al, 2010; Gizer et al, 2009; Guimaraes et al, 2009; Jensen et al, 2009; New et al, 2001; Zouk et al, 2007). The involvement of $5-\mathrm{HT}_{1 \mathrm{~B}} \mathrm{R}$ in impulsive behavior points to a potential target for the development of drugs to treat disordered impulsive action. This is further supported by the ability to restore normal impulsive action in mice lacking $5-\mathrm{HT}_{1 \mathrm{~B}} \mathrm{Rs}$ by rescuing receptor expression in adulthood. The circuit-level mechanisms by which the $5-\mathrm{HT}_{1 \mathrm{~B}} \mathrm{R}$ impacts impulsivity are still unknown and are the focus of our current research using tissue-specific knockout models.

Although the within-subject comparison across a number of different behavioral tests was necessary for the goal of our studies to use factor analyses, the experimental design by default also leads to some potential confounds, including order and age effects, that cannot be completely ruled out. Counterbalancing of the order of tests was not used due to previous reports of interactions between DRL performance, $5-\mathrm{HT}_{1 \mathrm{~B}} \mathrm{R}$ expression, and order of operant testing (Pattij et al, 2004). A previous study of impulsive choice found similar effects of $5-\mathrm{HT}_{1 \mathrm{~B}} \mathrm{R} \mathrm{KO}$ on $\mathrm{DD}$ when tested alone, although a slightly different paradigm was used which included different time delays and sucrose pellets instead of evaporated milk rewards (Brunner and Hen, 1997). Although the effect of age and order cannot definitively be ruled out as contributing factors to our results, these previous results support our interpretation that an absence of $5-\mathrm{HT}_{1 \mathrm{~B}} \mathrm{Rs}$ does not lead to increases in impulsive choice measured in a delay discounting paradigm. Additionally, all mice were re-run on the PR schedule of responding following PD, and showed a similar behavioral profile to that seen initially when tested as the second behavioral measure.

Although these data support the idea that general locomotor activity (measured in open field) and impulsive action (DRL, Go/No-Go) have common sources of variability, as shown by these measures loading on to the same factor, our results also draw distinctions between effects of $5-\mathrm{HT}_{1 \mathrm{~B}}$ on general activity $v s$ impulsive action. First, although there is a trend toward differences in open field behavior, there is no significant effect of group on total activity. Additionally, in the DRL task, increases in activity can be distinguished from premature responses based on the distribution of lever presses over latency. Premature responses are represented with a left shift in the distribution (decreases in the mode of response latencies), whereas increases in activity are seen in an increase in lever pressing across the response distribution as seen previously (Nautiyal et al, 2015). Finally, the relationship between impulsivity and hyperactivity in novel environments has been addressed in prior published studies. These studies have reported either no association or an inverse correlation between these measures (Bardo et al, 2006; Dalley et al, 2007).

Although the behavioral response on the progressive ratio schedule of responding loaded onto the impulsive action factor, the increased lever pressing may represent an increase in reward sensitivity in mice lacking $5-\mathrm{HT}_{1 \mathrm{~B}} \mathrm{R}$ expression. It is possible, that a reward is perceived as more rewarding to mice lacking $5-\mathrm{HT}_{1 \mathrm{~B}} \mathrm{R}$, and thus elicits higher responding in the progressive ratio schedule of responding and an increased preference for the large reward in the DD and PD tasks. We have analyzed the preference for a small $v s$ large (three times the small) reward in the absence of any delays or probabilities. Although there is a trend toward 
increased choice of the large reward, there was no significant effect of group. Despite this, the possibility still exists that $5-\mathrm{HT}_{1 \mathrm{~B}} \mathrm{R} \mathrm{KO}$ mice exhibit a hypersensitivity to reward, however, testing this would require a paradigm that compares the preference between KOs and controls at various ratios of large to small rewards.

Interestingly sex was a predictor of both factors, with males having higher levels of both impulsive action and choice. These findings are consistent with a higher prevalence of impulsive behavior in males compared with females in the general population (Chamorro et al, 2012). There is also a greater prevalence of disorders of impulse control, such as ADHD and substance use disorders, in males compared with females (Kessler et al, 2005; Rucklidge, 2010). Additionally, within ADHD, girls show less impulsive behavior than boys (Newcorn et al, 2001). Studies have also examined sex differences in impulsive action $v s$ choice components but the results have been mixed (Weafer and de Wit, 2014). In rodent models, the evidence generally supports increased impulsive action in males compared with females (Bayless et al, 2012; Jentsch and Taylor, 2003), with gonadectomy diminishing the sex difference. However, the data from human studies are less uniform, with reports of increased impulsive action in both males and females (Colzato et al, 2010; Saunders et al, 2008). Additionally, studies of sex differences in impulsive choice in both rodents and humans have been mixed (Beck and Triplett, 2009; Eubig et al, 2014; Kirby and Marakovic, 1996; Koot et al, 2009). More studies which address impulsivity which include both sexes are needed to clarify the role of sex in impulsivity and dissect potential interactions of serotonin signaling and sex on impulsive behavior.

In sum, more clear definitions of specific independent behavioral endophenotypes, as well as a novel entry point in the circuitry of impulsive behavior $\left(5-\mathrm{HT}_{1 \mathrm{~B}}\right)$ will allow for better ways to dissect the neural circuitry that modulate the different types of impulsive behavior. Specifically, a combination of cell-specific manipulations of the $5-\mathrm{HT}_{1 \mathrm{~B}}$ gene coupled with imaging strategies should enable us to make substantial progress in mapping the neural circuits underlying impulsive action. The dissociation of distinct components of impulsive behavior and the dissection of their neurobiological basis has broad implications for the construct of impulsivity and its relationship with psychiatric disorders. A better delineation of the underlying biobehavioral structure of impulsivity could lead to more etiologically based classification of disorders with pathological impulsivity and may inform better, more targeted pharmacological treatments.

\section{FUNDING AND DISCLOSURE}

Funding provided by NIH: F32 MH100888 to KMN, K99 MH106731 to KMN, R37 MH068542 to RH, R01 MH083862 to $\mathrm{RH}$, and R01 MH068073 to PDB. Funding also provided by the National Center for Responsible Gaming Early Stage Investigator Award to KMN; NARSAD Young Investigator Award to KMN; Hope for Depression Research Foundation Award to RH; and the New York State Psychiatric Institute to $\mathrm{CB}$. René Hen receives compensation as a consultant for Lundbeck and Roche. All other authors report no biomedical financial interests or potential conflicts of interest. The views and opinions expressed in this report are those of the authors and should not be construed to represent the views of any of the sponsoring organizations, agencies, or the US government.

\section{REFERENCES}

Banerjee E, Banerjee D, Chatterjee A, Sinha S, Nandagopal K (2012). Selective maternal inheritance of risk alleles and genetic interaction between serotonin receptor-1B (5-HTR1B) and serotonin transporter (SLC6A4) in ADHD. Psychiatry Res 200: 1083-1085.

Bardo MT, Cain ME, Bylica KE (2006). Effect of amphetamine on response inhibition in rats showing high or low response to novelty. Pharmacol Biochem Behav 85: 98-104.

Bari A, Robbins TW (2013). Inhibition and impulsivity: behavioral and neural basis of response control. Prog Neurobiol 108: 44-79.

Barrus MM, Hosking JG, Zeeb FD, Tremblay M, Winstanley CA (2015). Disadvantageous decision-making on a rodent gambling task is associated with increased motor impulsivity in a population of male rats. J Psychiatry Neurosci 40: 108-117.

Bayless DW, Darling JS, Stout WJ, Daniel JM (2012). Sex differences in attentional processes in adult rats as measured by performance on the 5-choice serial reaction time task. Behav Brain Res 235: 48-54.

Beck RC, Triplett MF (2009). Test-retest reliability of a groupadministered paper-pencil measure of delay discounting. Exp Clin Psychopharmacol 17: 345-355.

Berg JM, Latzman RD, Bliwise NG, Lilienfeld SO (2015). Parsing the heterogeneity of impulsivity: a meta-analytic review of the behavioral implications of the UPPS for psychopathology. Psychol Assess 27: 1129-1146.

Blanco C, Potenza MN, Kim SW, Ibanez A, Zaninelli R, Saiz-Ruiz J et al (2009). A pilot study of impulsivity and compulsivity in pathological gambling. Psychiatry Res 167: 161-168.

Broos N, Schmaal L, Wiskerke J, Kostelijk L, Lam T, Stoop N et al (2012). The relationship between impulsive choice and impulsive action: a cross-species translational study. PloS One 7: e36781.

Brunner D, Hen R (1997). Insights into the neurobiology of impulsive behavior from serotonin receptor knockout mice. Ann NY Acad Sci 836: 81-105.

Chamorro J, Bernardi S, Potenza MN, Grant JE, Marsh R, Wang S et al (2012). Impulsivity in the general population: a national study. J Psychiatr Res 46: 994-1001.

Colzato LS, Hertsig G, van den Wildenberg WP, Hommel B (2010). Estrogen modulates inhibitory control in healthy human females: evidence from the stop-signal paradigm. Neuroscience 167: 709-715.

Conner TS, Jensen KP, Tennen H, Furneaux HM, Kranzler HR, Covault J (2010). Functional polymorphisms in the serotonin 1B receptor gene (HTR1B) predict self-reported anger and hostility among young men. Am J Med Genet 153B: 67-78.

Dalley JW, Everitt BJ, Robbins TW (2011). Impulsivity, compulsivity, and top-down cognitive control. Neuron 69: 680-694.

Dalley JW, Fryer TD, Brichard L, Robinson ES, Theobald DE, Laane K et al (2007). Nucleus accumbens D2/3 receptors predict trait impulsivity and cocaine reinforcement. Science 315: 1267-1270.

Dawe S, Loxton NJ (2004). The role of impulsivity in the development of substance use and eating disorders. Neurosci Biobehav Rev 28: 343-351.

Dougherty DM, Mathias CW, Marsh-Richard DM, Furr RM, Nouvion SO, Dawes MA (2009). Distinctions in behavioral impulsivity: implications for substance abuse research. Addict Disord Treat 8: 61-73.

Drew MR, Simpson EH, Kellendonk C, Herzberg WG, Lipatova O, Fairhurst $S$ et al (2007). Transient overexpression of striatal D2 
receptors impairs operant motivation and interval timing. J Neurosci 27: 7731-7739.

Eubig PA, Noe TE, Floresco SB, Sable JJ, Schantz SL (2014). Sex differences in response to amphetamine in adult Long-Evans rats performing a delay-discounting task. Pharmacol Biochem Behav 118: $1-9$.

Frijda NH (2010). Impulsive action and motivation. Biol Psychol 84: 570-579.

Gizer IR, Ficks C, Waldman ID (2009). Candidate gene studies of ADHD: a meta-analytic review. Hum Genet 126: 51-90.

Guimaraes AP, Schmitz M, Polanczyk GV, Zeni C, Genro J, Roman $\mathrm{T}$ et al (2009). Further evidence for the association between attention deficit/hyperactivity disorder and the serotonin receptor 1B gene. J Neural Transm 116: 1675-1680.

Hepler J, Albarracin D, McCulloch KC, Noguchi K (2012). Being active and impulsive: the role of goals for action and inaction in self-control. Motiv Emot 36: 416-424.

Insel TR, Cuthbert BN (2015). Medicine. Brain disorders? Precisely. Science 348: 499-500.

Jensen KP, Covault J, Conner TS, Tennen H, Kranzler HR, Furneaux HM (2009). A common polymorphism in serotonin receptor 1B mRNA moderates regulation by miR-96 and associates with aggressive human behaviors. Mol Psychiatry 14: 381-389.

Jentsch JD, Taylor JR (2003). Sex-related differences in spatial divided attention and motor impulsivity in rats. Behav Neurosci 117: 76-83.

Joreskog KG, Goldberger AS (1975). Estimation of a model with multiple indicators and multiple causes of a single latent variable. J Am Stat Assoc 70: 631-639.

Kessler RC, Berglund P, Demler O, Jin R, Merikangas KR, Walters EE (2005). Lifetime prevalence and age-of-onset distributions of DSM-IV disorders in the National Comorbidity Survey Replication. Arch Gen Psychiatry 62: 593-602.

Kirby KN, Marakovic NN (1996). Delay-discounting probabilistic rewards: rates decrease as amounts increase. Psychon Bull Rev 3: $100-104$.

Koot S, van den Bos R, Adriani W, Laviola G (2009). Gender differences in delay-discounting under mild food restriction. Behav Brain Res 200: 134-143.

MacKillop J, Weafer J, C Gray J, Oshri A, Palmer A, de Wit H (2016). The latent structure of impulsivity: impulsive choice, impulsive action, and impulsive personality traits. Psychopharmacology 233: 3361-3370.

Mar AC, Robbins TW (2007). Delay discounting and impulsive choice in the rat. Curr Protoc Neurosci Chapter 8: Unit 822.

McDonald J, Schleifer L, Richards JB, de Wit H (2003). Effects of THC on behavioral measures of impulsivity in humans. Neuropsychopharmacology 28: 1356-1365.

Meda SA, Stevens MC, Potenza MN, Pittman B, Gueorguieva R, Andrews MM et al (2009). Investigating the behavioral and selfreport constructs of impulsivity domains using principal component analysis. Behav Pharmacol 20: 390-399.

Michaelis BH, Goldberg JF, Davis GP, Singer TM, Garno JL, Wenze SJ (2004). Dimensions of impulsivity and aggression associated with suicide attempts among bipolar patients: a preliminary study. Suicide Life Threat Behav 34: 172-176.

Miyazaki KW, Miyazaki K, Doya K (2012). Activation of dorsal raphe serotonin neurons is necessary for waiting for delayed rewards. J Neurosci 32: 10451-10457.

Miyazaki KW, Miyazaki K, Tanaka KF, Yamanaka A, Takahashi A, Tabuchi S et al (2014). Optogenetic activation of dorsal raphe serotonin neurons enhances patience for future rewards. Curr Biol 24: 2033-2040.

Moeller FG, Barratt ES, Dougherty DM, Schmitz JM, Swann AC (2001). Psychiatric aspects of impulsivity. Am J Psychiatry 158: $1783-1793$.
Muthen LK, Muthen BO (1998-2010). Mplus user's guide, 6th edn. Muthen \& Muthen: Los Angeles.

National Institutes of Health (2015). NIH-Wide Strategic Plan: Fiscal Years 2016-2020. U.S. Government Printing Office: Washington, DC.

Nautiyal KM, Tanaka KF, Barr MM, Tritschler L, Le Dantec Y, David DJ et al (2015). Distinct circuits underlie the effects of 5-ht1b receptors on aggression and impulsivity. Neuron 86: 813-826.

New AS, Gelernter J, Goodman M, Mitropoulou V, Koenigsberg H, Silverman J et al (2001). Suicide, impulsive aggression, and HTR1B genotype. Biol Psychiatry 50: 62-65.

Newcorn JH, Halperin JM, Jensen PS, Abikoff HB, Arnold LE, Cantwell DP et al (2001). Symptom profiles in children with ADHD: effects of comorbidity and gender. J Am Acad Child Adolesc Psychiatry 40: 137-146.

Pattij T, Broersen LM, Peter S, Olivier B (2004). Impulsive-like behavior in differential-reinforcement-of-low-rate $36 \mathrm{~s}$ responding in mice depends on training history. Neurosci Lett 354: 169-171.

Pattij T, Broersen LM, van der Linde J, Groenink L, van der Gugten J, Maes RA et al (2003). Operant learning and differentialreinforcement-of-low-rate 36-s responding in 5-HT1A and 5-HT1B receptor knockout mice. Behav Brain Res 141: 137-145.

Perez-Moreno E, Hernandez-Lloreda MJ, Gallego-Largo TR, Castellanos MA (2015). Impulsive driving: definition and measurement using the i-driving scale (IDS). Span J Psychol 18: E93.

Reynolds B, Ortengren A, Richards JB, de Wit H (2006). Dimensions of impulsive behavior: personality and behavioral measures. Pers Indiv Differ 40: 305-315.

Reynolds B, Penfold RB, Patak M (2008). Dimensions of impulsive behavior in adolescents: laboratory behavioral assessments. Exp Clin Psychopharmacol 16: 124-131.

Robbins TW, Gillan CM, Smith DG, de Wit S, Ersche KD (2012). Neurocognitive endophenotypes of impulsivity and compulsivity: towards dimensional psychiatry. Trends Cogn Sci 16: 81-91.

Rucklidge JJ (2010). Gender differences in attention-deficit/ hyperactivity disorder. Psychiatr Clin North Am 33: 357-373.

Saunders B, Farag N, Vincent AS, Collins FL Jr., Sorocco KH, Lovallo WR (2008). Impulsive errors on a Go-NoGo reaction time task: disinhibitory traits in relation to a family history of alcoholism. Alcohol Clin Exp Res 32: 888-894.

St Onge JR, Floresco SB (2009). Dopaminergic modulation of risk-based decision making. Neuropsychopharmacology 34: 681-697.

Story GW, Moutoussis M, Dolan RJ (2015). A computational analysis of aberrant delay discounting in psychiatric disorders. Front Psychol 6: 1948.

Swann AC (2011). Antisocial personality and bipolar disorder: interactions in impulsivity and course of illness. Neuropsychiatry 1: $599-610$.

Van den Bergh F, Spronk M, Ferreira L, Bloemarts E, Groenink L, Olivier B et al (2006a). Relationship of delay aversion and response inhibition to extinction learning, aggression, and sexual behaviour. Behav Brain Res 175: 75-81.

van den Bergh FS, Bloemarts E, Groenink L, Olivier B, Oosting RS (2006b). Delay aversion: effects of 7-OH-DPAT, 5-HT1A/1Breceptor stimulation and D-cycloserine. Pharmacol Biochem Behav 85: 736-743.

Wang Q, Chen C, Cai Y, Li S, Zhao X, Zheng L et al (2016). Dissociated neural substrates underlying impulsive choice and impulsive action. NeuroImage 134: 540-549.

Weafer J, Baggott MJ, de Wit H (2013). Test-retest reliability of behavioral measures of impulsive choice, impulsive action, and inattention. Exp Clin Psychopharmacol 21: 475-481. 
Weafer J, de Wit H (2014). Sex differences in impulsive action and impulsive choice. Addic Behav 39: 1573-1579.

Winstanley CA (2011). The utility of rat models of impulsivity in developing pharmacotherapies for impulse control disorders. Br J Pharmacol 164: 1301-1321.

Winstanley CA, Dalley JW, Theobald DE, Robbins TW (2003). Global 5-HT depletion attenuates the ability of amphetamine to decrease impulsive choice on a delay-discounting task in rats. Psychopharmacology 170: 320-331.

Winstanley CA, Dalley JW, Theobald DE, Robbins TW (2004). Fractionating impulsivity: contrasting effects of central 5-HT depletion on different measures of impulsive behavior. Neuropsychopharmacology 29: 1331-1343.

Worbe Y, Savulich G, Voon V, Fernandez-Egea E, Robbins TW (2014). Serotonin depletion induces 'waiting impulsivity' on the human four choice serial reaction time task: cross-species translational significance. Neuropsychopharmacology 39: 1519-1526.

Zouk H, McGirr A, Lebel V, Benkelfat C, Rouleau G, Turecki G (2007). The effect of genetic variation of the serotonin $1 \mathrm{~B}$ receptor gene on impulsive aggressive behavior and suicide. Am J Med Genet B Neuropsychiatr Genet 144B: 996-1002.

Supplementary Information accompanies the paper on the Neuropsychopharmacology website (http://www.nature.com/npp) 